\title{
A complex rearrangement associated with sex reversal and the Wolf-Hirschhorn syndrome: a cytogenetic and molecular study
}

\author{
Katrina Coles, Moira Mackenzie, John Crolla, John Harvey, Julia Starr, Frances \\ Howard, Patricia Jacobs
}

\begin{abstract}
We report a male infant referred with multiple congenital abnormalities consistent with the Wolf-Hirschhorn syndrome. Cytogenetic analysis showed a chromosome complement of $46, X X$ with a deletion of 4 p15.2 $\rightarrow 4$ pter and its replacement by material of unknown origin. The patient was positive for a number of $Y p$ probes including SRY, the testis determining factor, and in situ hybridisation localised the Yp material to the tip of the short arm of one $X$ chromosome. Using pDP230, a probe for the pseudoautosomal region, and $M 27 \beta$, which recognises a locus in proximal $X p$, the material translocated on to $4 p$ was identified as originating from the short arm of the paternal $X$ chromosome.

The most reasonable explanation for this complex rearrangement is two separate exchange events involving both chromatids of $\mathrm{Xp}$ during paternal meiosis. An aberrant $X-Y$ interchange gave rise to the sex reversal and an $X ; 4$ translocation resulted in additional, apparently active $X p$ material and a deletion of $4 p$ which produced the Wolf-Hirschhorn phenotype.
\end{abstract}

The Wolf-Hirschhorn syndrome is a rare chromosome disorder associated with a partial deletion of the short arm of chromosome 4 . It is now a well defined clinical entity with characteristic facial and other anomalies accompanied by profound growth and developmental delay. In spite of severe malformations patients may survive well beyond infancy. ${ }^{1}$

Lurie et $a l^{2}$ suggested that about $13 \%$ of cases of the Wolf-Hirschhorn syndrome result from translocations, with inheritance in familial cases equally likely to be from the mother or father. Recent reports suggest that in cases resulting from de novo deletions or rearrangements of $4 p$ the abnormality usually involves the paternal chromosome. ${ }^{3}$

The incidence of phenotypic males with a $46, \mathrm{XX}$ karyotype is approximately $1 / 20000$ males. ${ }^{4}$ Most cases are the result of an aberrant $\mathrm{X}-\mathrm{Y}$ interchange during paternal meiosis, resulting in the transfer of Yp material, including the testis determining gene SRY, to the distal short arm of the $\mathrm{X}$ chromosome, as shown by Southern blot analysis followed by in situ hybridisation. ${ }^{5-7}$
Mattei et $a l^{8}$ estimated the incidence of $\mathrm{X}$;autosome translocations as 1 to 3 per 10000 live births with approximately one-third of cases being unbalanced. Over half the published reports of unbalanced $\mathrm{X}$;autosome translocations have a normal $\mathrm{X}$ chromosome replaced by the derived $X$. Of the remainder, most are the result of adjacent II or $3: 1$ segregation, in approximately equal numbers. It is unusual to find the autosomal derivative with two normal sex chromosomes, resulting from adjacent I segregation. Mattei et $a l^{8}$ cited three cases out of a total of 44 unbalanced $\mathrm{X}$;autosome translocations. In each case the mother carried the balanced translocation, which allowed recognition of the derived chromosome. However, it is not uncommon to find patients carrying a rearranged autosome where the origin of the translocated material cannot be identified. Such abnormal chromosomes may contain $\mathrm{X}$ chromosome material making the recognition of de novo unbalanced $X$;autosome translocations, carrying the autosomal derivative in place of a normal autosome, difficult. Thus, such patients may be more common in the population than suggested by the data of Mattei et al. ${ }^{8}$

This report describes such a patient, with an unbalanced $X ; 4$ translocation giving rise to the Wolf-Hirschhorn syndrome, and, in addition, sex reversal resulting from an aberrant $X-Y$ interchange.

\section{Case report}

The patient was born at 41 weeks to a 21 year old mother who already had two normal sons; the father was aged 24. Birth weight was $2400 \mathrm{~g}$, head circumference $30.2 \mathrm{~cm}$, and length $44 \mathrm{~cm}$. The placenta weighed $550 \mathrm{~g}$.

At birth he was growth retarded, had microcephaly with frontal bossing, haemangioma of the forehead, and apparent left proptosis as the right eye was micropthalmic with an iris and a choroidal coloboma; the left eye had a very small choroidal coloboma. He also had a broad, beaked nose, blocked nasolacrimal ducts, a very short philtrum, everted upper lip, downturned corners of the mouth, a small mandible, and a cleft palate. The left ear was floppy and misshapen and the right ear posteriorly rotated, the long narrow chest had nipples at different heights, and he had finger-like thumbs. Genitalia were obviously male, but he had a short penis with a hypospadias and a small scrotum, though gonads were palpable. He also had a sacral sinus, umbilical hernia, 
and low anal tone. Kidney and brain ultrasound were normal as were ECG and the heart. A third fontanelle was palpable at birth.

Although the patient was initially referred with ?CHARGE syndrome, the phenotype was later agreed to be consistent with a clinical diagnosis of Wolf-Hirschhorn $(4 \mathrm{p}-)$ syndrome.

At 7 weeks the patient smiled, at 5 months he laughed and turned his head to his mother's voice, and by 9 months he could sit well and get both hands to the midline but could not reach or hold. At 17 months his weight was $6.5 \mathrm{~kg}$, head circumference $42 \mathrm{~cm}$, and length $70 \mathrm{~cm}$, all three well below the $3 \mathrm{rd}$ centile. $\mathrm{He}$ could roll from back to side and sat well with support. He would play with both hands together but would not transfer, that is, 5 month stage of development (fig 1).

By 3 years of age he was in the 1 year skills and size range: head circumference $44 \mathrm{~cm}$, weight $7.78 \mathrm{~kg}$. He was sitting alone, casting, nodding for 'yes' and shaking his head for 'no', but had no words. He developed bilateral glue ears and has occasional fits which are well controlled with carbamazepine.

\section{Materials and methods \\ CYTOGENETICS}

Chromosome studies were performed on peripheral blood lymphocytes. Three day cultures were released from an excess thymidine block with deoxycytidine enriched medium and harvested by standard methods to produce prometaphase chromosomes which were then $G$ banded. ${ }^{9}$ Replication banding was produced by the incorporation of $30 \mu \mathrm{g} / \mathrm{ml}$ bromodeoxyuridine (BudR) for six hours before harvesting. Metaphases were stained with $0 \cdot 1 \%$ acridine orange in phosphate buffer and viewed under epifluorescence. One hundred cells were scored to establish replication status.

\section{IN SITU HYBRIDISATION}

Chromosome preparations were made from peripheral blood lymphocytes, skin fibroblasts, and lymphoblastoid cell lines, using standard cell culture techniques. BudR was added before harvesting in order to achieve late replication banding. Metaphase spreads were hybridised in situ according to a modification of the method of Buckle and Craig. ${ }^{10}$ Probes were labelled with tritiated dATP and $\mathrm{dCTP}$ to counts of $1.2 \times 10^{8} \mathrm{dpm} / \mu \mathrm{g} \mathrm{DNA}$ (probe p75/79) and $3.6 \times 10^{7} \mathrm{dpm} / \mu \mathrm{g}$ DNA (probe pDP230). After exposure for two to four weeks the chromosomes were stained in Hoechst 33258, exposed to UV for one hour, and stained with Giemsa to give replication $\mathbf{R}$ banding. The probes used were p75/79 (locus $D X Y S 25),{ }^{6}$ which maps to $\mathrm{Yp}$, proximal to SRY the putative TDF, and pDP230 (locus DXYS20), "1 a pseudoautosomal probe recognising sequences at the tips of the $\mathrm{X}$ and $\mathrm{Y}$ chromosomes.
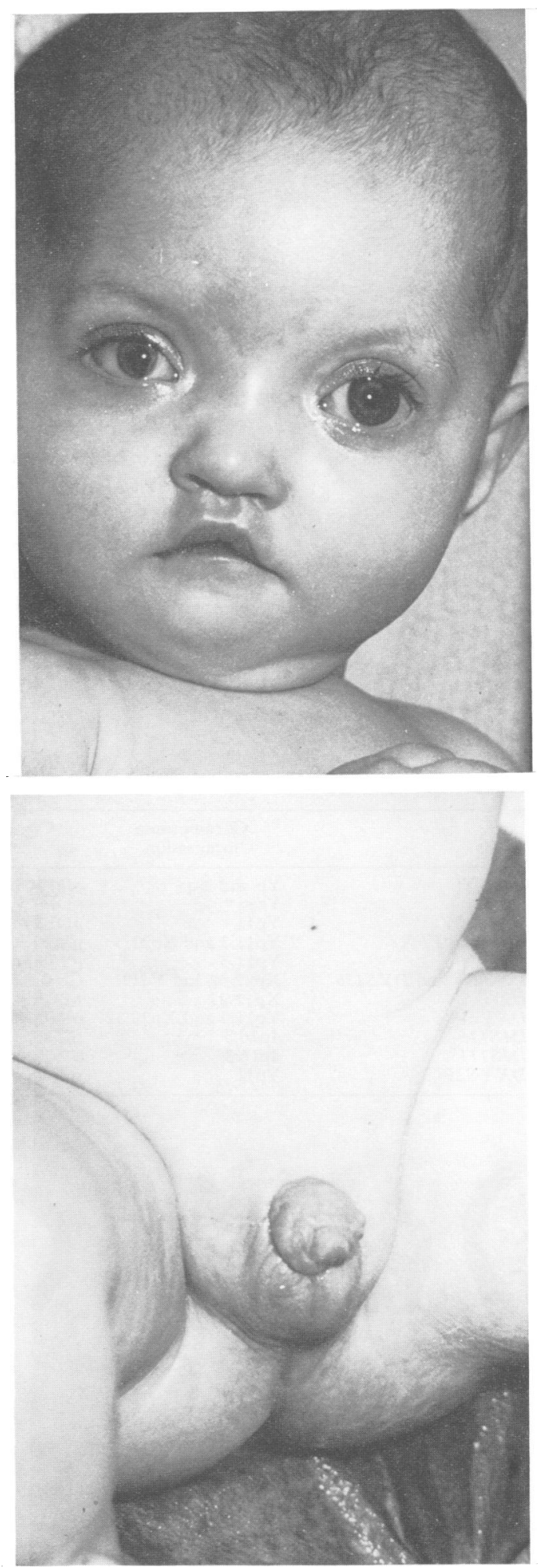

Figure 1 The patient aged 2 years and the external genitalia.

\section{MOLECULAR STUDIES}

DNA was extracted from whole blood by a salt precipitation technique, ${ }^{12}$ digested with appropriate restriction enzymes, separated by agarose gel electrophoresis, and transferred to nylon membranes. For the hybridisation DNA probes were labelled with ${ }^{32} \mathrm{P}$ by random primer techniques. ${ }^{13}$ Details of the probes used are given in the table.

Several Y probes were used, spanning the centromere and short arm. Pseudoautosomal and $\mathrm{X}$ specific probes were used to determine 
the parental origin of the $\mathrm{X}$ chromosomes. $\mathrm{M} 27 \beta$ is an $\mathrm{X}$ probe recognising a sequence that is non-methylated on inactive and methylated on active $\mathrm{X}$ chromosomes; after digestion with $M s p I$ and its methylation sensitive isoschizomer HpaII, the inactivation status of $\mathrm{X}$ chromosomes can be determined. A number of probes for the short arm of chromosome 4 were used but only two were found to be informative and are included in the table.

\section{Results}

CYTOGENETICS

$G$ banded chromosome analysis showed the patient to have a complement of $46, \mathrm{XX}$ with an abnormality of the short arm of one chromosome 4. The terminal segment was deleted, with a breakpoint at 4 p15.2, and additional, unidentified material translocated on to the deleted chromosome (fig 2). Replication banding showed that this material was early replicating, suggesting that it was active. The

Probes used.

\begin{tabular}{llllc}
\hline Locus & \multicolumn{1}{c}{$\begin{array}{c}\text { Chromosome } \\
\text { localisation }\end{array}$} & \multicolumn{1}{c}{ Probe } & Enzyme & Reference \\
\hline$D Y Z 4$ & Yp and Yq & pDP105 & TaqI & 14 \\
$D Y Z 3$ & Ycen & pDP97 & EcoRI & 14 \\
$D X Y S 1 Y$ & Yp11 & pDP34 & MspI & 15 \\
YFY and $Z F X$ & Yp11.3 and Xp21.3 & pMF1 & EcoRI & 16 \\
SRY & Yp11.3 & pY53.3 & HindIII & 17 \\
$D X S 278$ and $D Y S 136$ & Xp22.32 and Yq11 & CR1-S232 & TaqI & 18 \\
$D X S 255$ & Yp11.22 & M27ß & EcoRI & 19 \\
$D X Y S 20$ & 4p16.3 and Xp22.32 & pDP230 & TaqI & 11 \\
$D 4 S 115$ & 4p16.3 & p252.3 & PstI & 20 \\
$D 4 S 111$ & Yp11 & p157.9 & PstI & 20 \\
$D X Y S 25$ & & p75/79 & & 6 \\
\hline
\end{tabular}

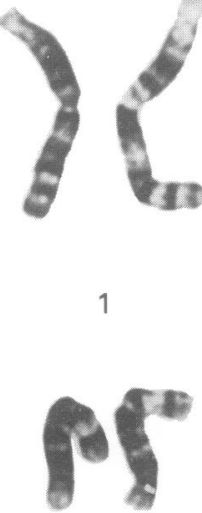

6

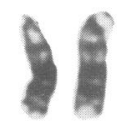

13

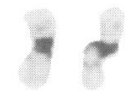

19
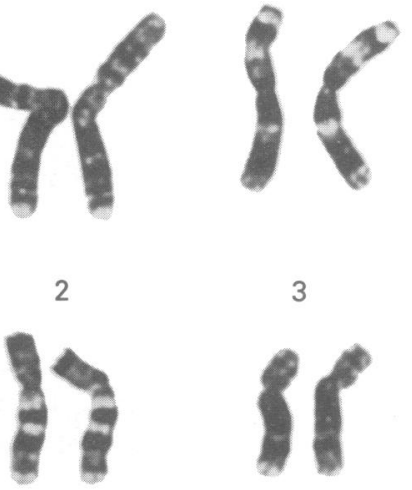

7

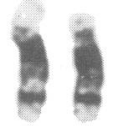

14

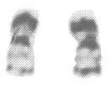

3

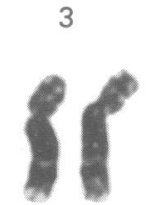

8

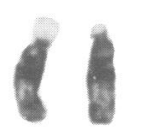

15

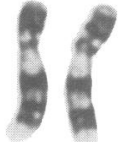

9

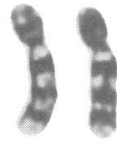

10

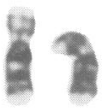

16 deleted segment of the chromosome 4 includes the 'critical region' associated with the WolfHirschhorn syndrome. ${ }^{22}$ Parental chromosomes were normal.

\section{MOLECULAR}

The patient had an XX sex chromosome complement but a male phenotype, so the presence or absence of $Y$ material had to be determined. Southern blot analysis using $\mathrm{Y}$ probes showed that the patient was negative for $D Y Z 4$, $D Y Z 3$, and $D X Y S 1 Y$, loci spanning Yq11 to proximal Yp11, and positive for ZFY and SRY, the putative testis determining gene (fig 3). These results indicated that distal Yp material was present somewhere in the patient's karyotype. The localisation of the $\mathrm{Yp}$ sequences was determined by in situ hybridisation using the $\mathrm{Yp}$ specific probe $\mathrm{p} 75 / 79$. Forty-three metaphases were scored and the distribution of 145 grains showed that 28 $(19.3 \%)$ were on an X chromosome, with 16 located at the terminal region Xp2.2 $\rightarrow$ Xpter (fig 4). In all metaphases examined, only one of the $\mathrm{X}$ chromosomes was labelled. The patient therefore had Yp material translocated to the tip of one $\mathrm{X}$ chromosome owing to an aberrant $\mathrm{X}-\mathrm{Y}$ interchange at paternal meiosis I. Thus, with respect to his sex reversal the patient was a classic XX male.

As the additional material on $4 p$ was not of $Y$ origin, its identity was investigated. Southern blot analysis using the pseudoautosomal probe pDP230 showed the patient to have inherited all his father's bands but only some of his mother's (fig 5). This suggested that he had inherited three copies of the pseudoautosomal
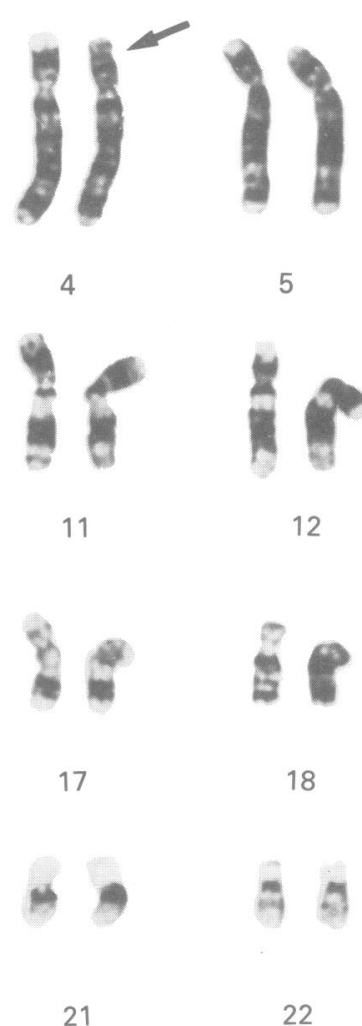

Figure $2 G$ banded karyotype of the patient showing the abnormal chromosome 4 (arrowed). 
Figure 3 Southern blot of probes for $Z F Y$ and $S R Y$ showing the same bands present in the patient and his father. The $1.7 \mathrm{~kb}$ band also detected in the mother is a $Z F X$ fragment.

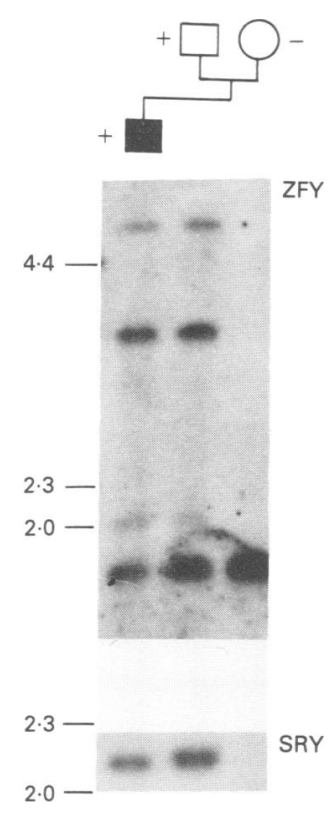

This was formally proved by in situ hybridisation using the pseudoautosomal probe pDP230. Sixty-four metaphases were scored and the distribution of 155 grains showed that $13(8.4 \%)$ were on Xpter and $11(7 \%)$ were on 4 pter. The patient's karyotype is therefore $46, \mathrm{XX},-4,+\operatorname{der}(4) \mathrm{t}(\mathrm{X} ; 4)(\mathrm{p} 22.1 ; \mathrm{p} 15.2)$.

The Southern blot analysis and in situ hybridisation with the pseudoautosomal probe showed that the patient had two copies of the paternal pseudoautosomal region and one copy of the maternal pseudoautosomal region, and furthermore that one copy was translocated on to $4 \mathrm{p}$. However, while the $\mathrm{X}-\mathrm{Y}$ interchange leading to the translocation of $\mathrm{Y}$ material on to one $\mathrm{X}$ chromosome must have happened during the paternal first meiotic division, we had no formal proof of the parental origin of the normal $X$ and the $X ; 4$ translocation chromosome. We therefore used probe $M 27 \beta$, which recognises sequences on proximal $\mathrm{Xp}$, and showed that the patient had inherited an $\mathrm{X}$ chromosome from each parent (fig 7A). Thus, the normal $X$ must have been maternal in origin. Furthermore, as $M 27 \beta$ recognises a sequence which is differentially methylated on

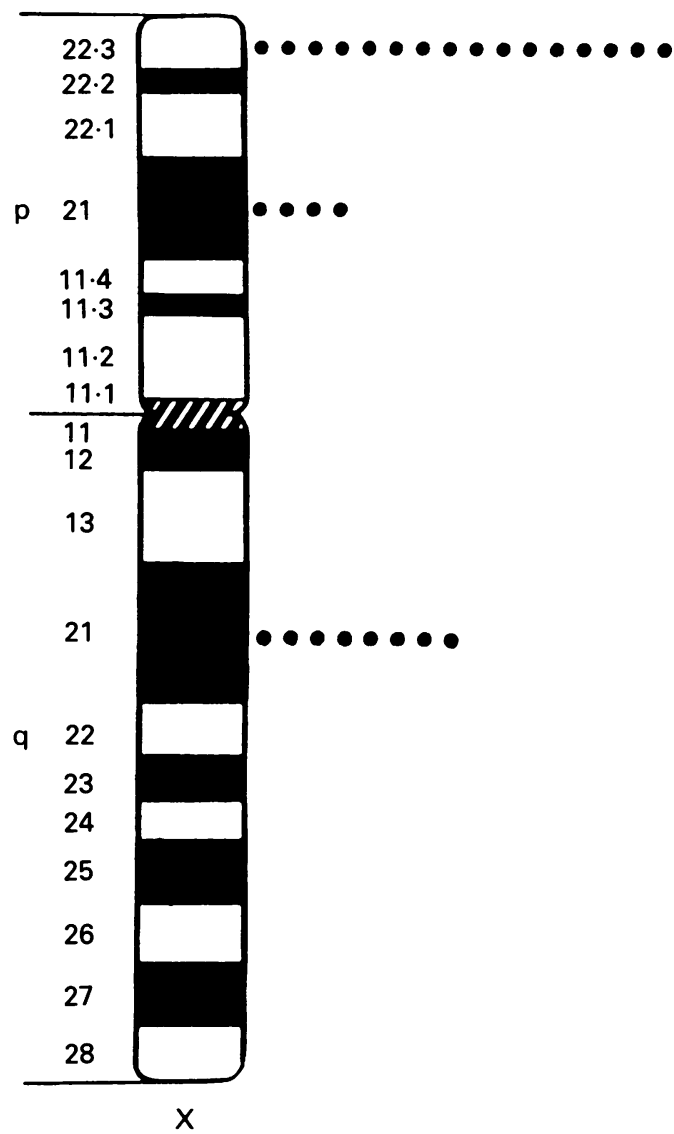

region, two from his father and one from his mother. If the copies from his father's $Y$ and one of his mother's Xs are on the patient's two $\mathrm{X}$ chromosomes, the copy from his father's $\mathrm{X}$ must also be present in the karyotype. This result suggested that the unidentified material on $4 \mathrm{p}$ was likely to be of $\mathrm{Xp}$ origin. Prometaphase chromosomes were re-examined and the banding pattern of the translocated segment was entirely consistent with it being the distal segment of the short arm of an X chromosome, specifically Xp22.1 $\rightarrow$ Xpter (fig 6).

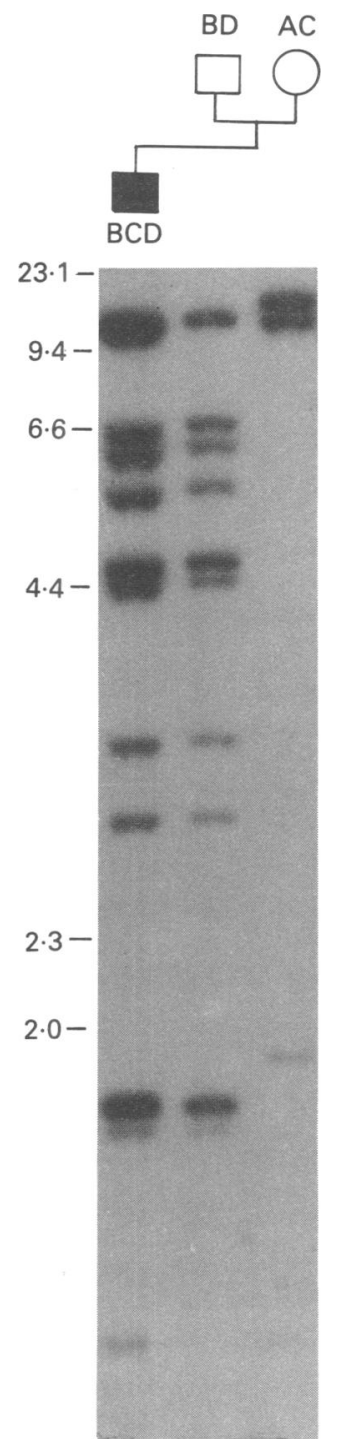

Figure 5 Southern blot of the pseudoautosomal probe pDP230. The patient has inherited all his father's bands but only some of his mother's. 
Figure 6 Partial karyotype showing the correspondence in banding between the distal short arm segments of the abnormal 4 and $X$ chromosomes.

Figure 7 (A) Southern blot of probe $M 27 \beta$. The patient has inherited one allele from each parent. (B) Southern blot of $M 27 \beta$ after digestion with $\operatorname{MspI}(M)$ and $H p a I I(H)$. The HpaII digests show the absence of $a$ band in the father and the reduced intensity of the bands in the mother and patient. The patient's two bands are of equal intensity, indicating random $X$ inactivation.
A

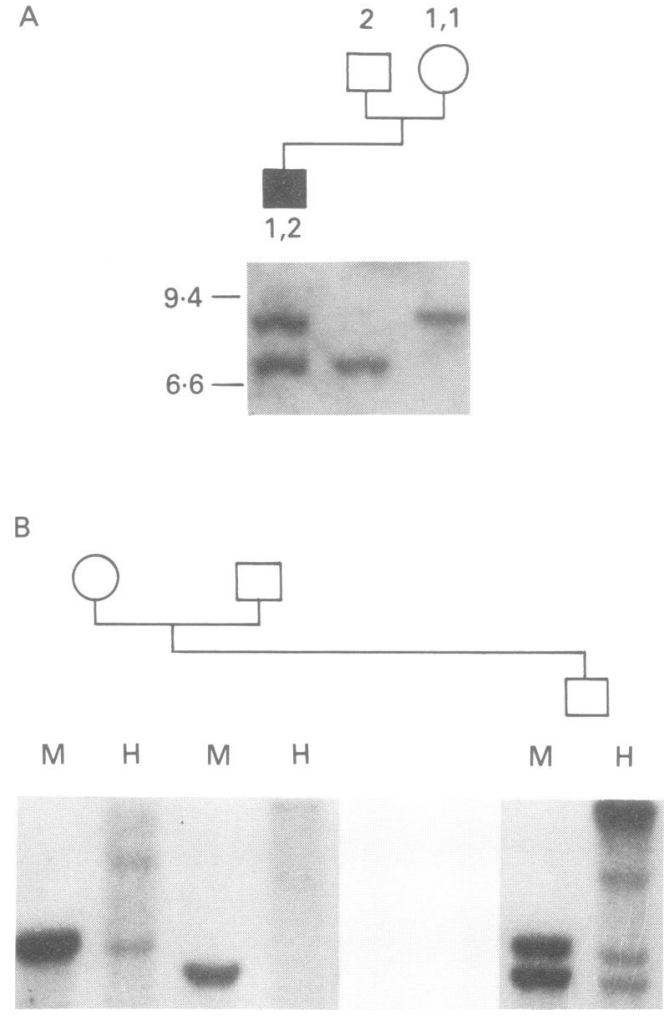

$B$

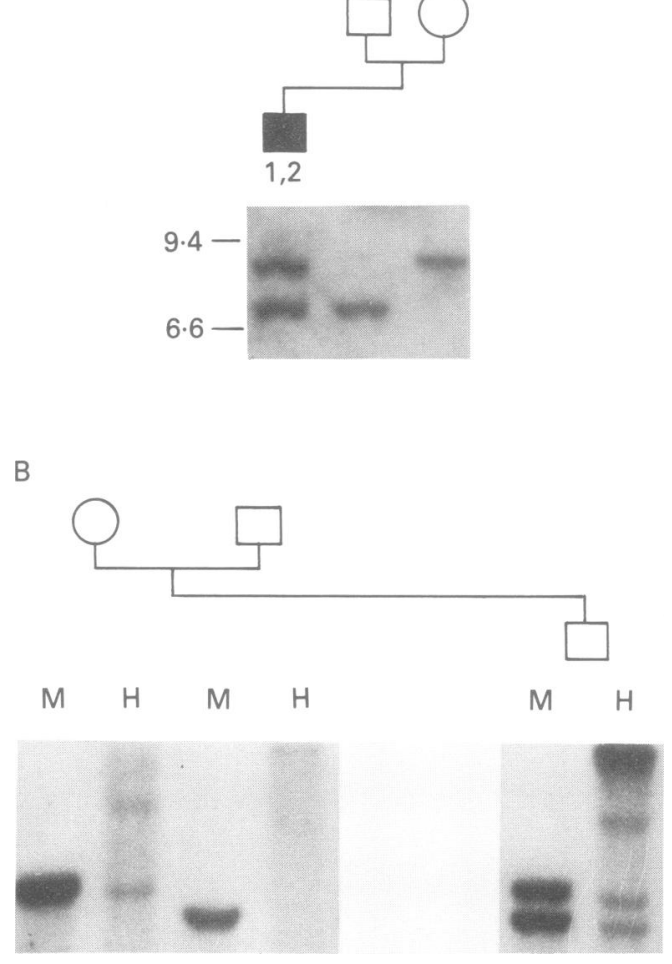

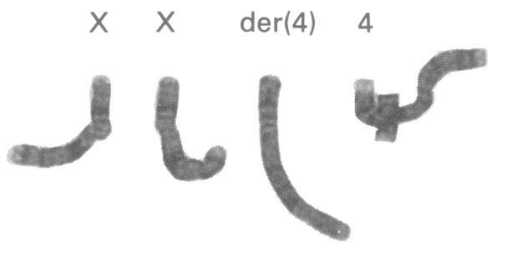

active and inactive $\mathrm{X}$ chromosomes, we were able to show that the $\mathrm{X}$ inactivation pattern in the patient's peripheral blood cells was random (fig 7B). As the normal $X$ was maternal and the abnormal $X$ paternal in origin the $X ; 4$ translocation chromosome must also be paternal in origin. This was formally demonstrated by testing the patient and his parents with 12 probes for loci on 4p16. Only two probes were informative and both showed that the patient had inherited one allele from his mother, but no allele from his father. This established that the derived chromosome 4 was indeed paternal in origin (fig 8).

Southern blot analysis using the probe CRI-S232, which recognises a sequence just proximal to the pseudoautosomal boundary, showed the patient to have only two copies of the locus, one paternal and one maternal. This defines the $\mathrm{X}-\mathrm{Y}$ interchange as being proximal to $D X S 278$, and therefore also the STS locus on the X (fig 9).

Our explanation for the observations in this patient is that two interchange events occurred during paternal meiosis. The first, involving an $\mathrm{X}$ and a $\mathrm{Y}$ chromatid must have taken place at meiosis $I$ and gave rise to the sex reversal. The second, involving a chromosome 4 and the other X chromatid, occurred at either meiosis I or prophase of meiosis II and gave the additional, apparently active $\mathrm{Xp}$ material and a

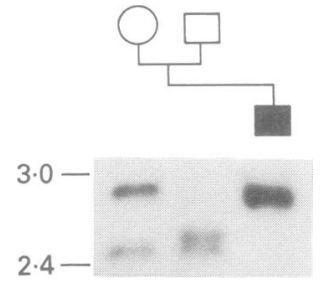

Figure 8 Southern blot of probe p252.3. The patient has inherited one allele (indicating the normal chromosome 4) from his mother but neither allele (indicating the deleted 4 ) from his father.

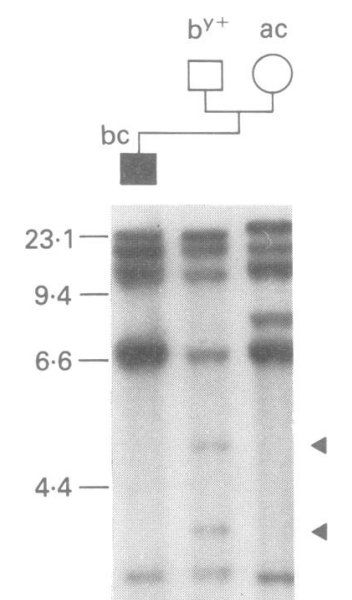

Figure 9 Southern blot of probe CR1-S232. The patient has inherited a single dose of his father's $X$, but not his $Y$ specific bands (arrowed) and some of his mother's bands.

deletion of distal $4 \mathrm{p}$ which produced the WolfHirschhorn phenotype. Therefore, both chromatids of one $\mathrm{X}$ chromosome had been involved in separate exchange events during paternal meiosis (fig 10).

\section{Discussion}

Previous reports of unbalanced X;autosome translocations suggest that where the autosomal derivative occurs with two $\mathrm{X}$ chromosomes the translocated $\mathrm{X}$ material is usually inactivated (in addition to a normal $\mathrm{X}$ chromosome) if it includes the inactivation centre on Xq. ${ }^{23-25}$ A similar case to ours described a female with a derived chromosome 6 carrying $\mathrm{Xp}$ material, specifically $\mathrm{Xp} 21 \rightarrow$ pter, which was apparently early replicating in all cells. ${ }^{26}$ The patient showed minor abnormalities and delayed psychomotor development, while her height, weight, and head circumference were below the 3 rd centile. The malformations were presumed to result from the deletion of chromosome 6 (q26 $\rightarrow$ qter).

Nearly all the clinical features shown by our patient have been previously reported in association with the Wolf-Hirschhorn syndrome. $^{2127}$ Only his finger-like thumbs and nipples at different heights have not been specifically associated with the syndrome, but other finger, thumb, and nipple abnormalities have been described. ${ }^{28}$ 

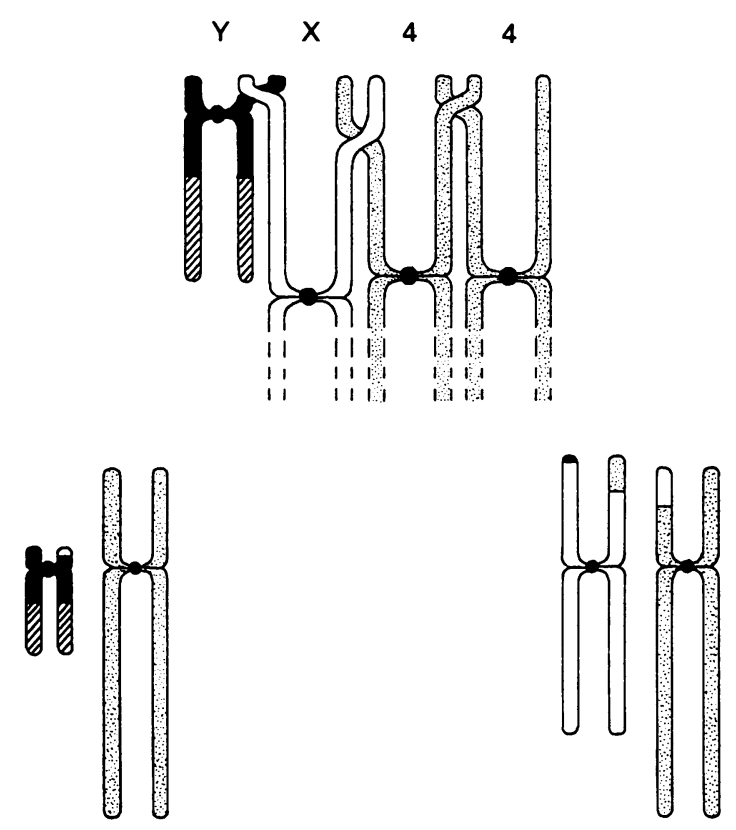

Meiosis II
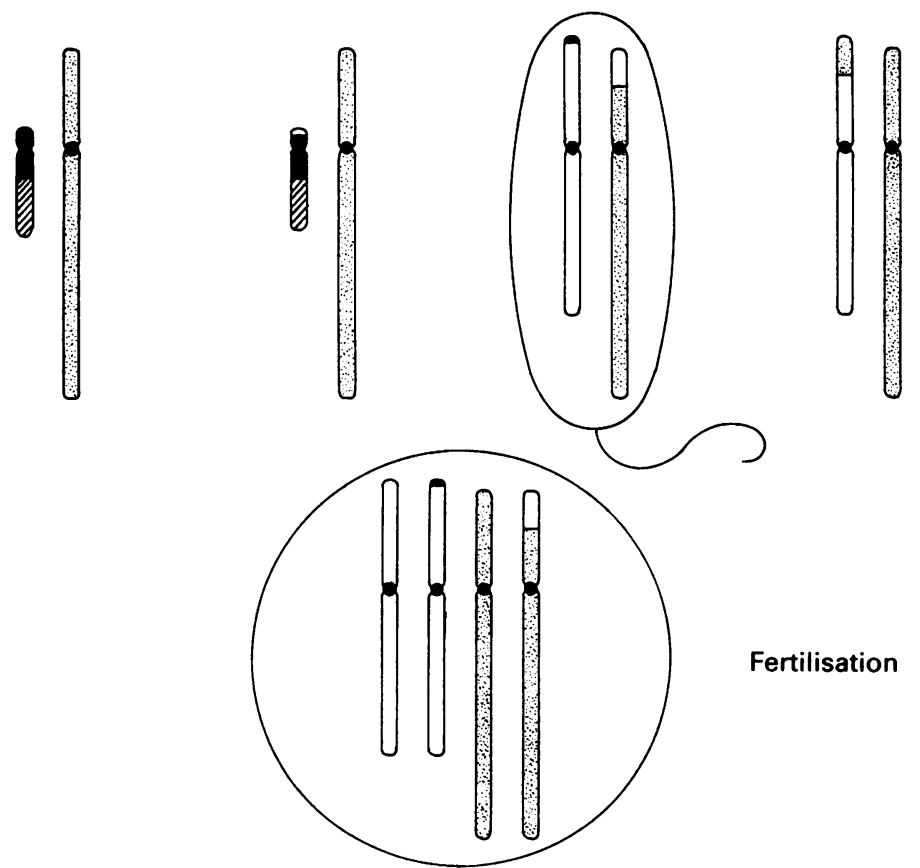

Sperm

Fertilisation

Figure 10 A diagrammatic representation of the two interchange events occurring at paternal meiosis I and their outcome. The $X ; 4$ exchange could alternatively have occurred during prophase of meiosis II.

The extra, active $\mathrm{Xp}$ material may have no phenotypic effect on the patient, or any abnormalities it does bestow fall within, or are modified by, the spectrum of Wolf-Hirschhorn associated features.

The only published report of a male with a duplication of Xp22 describes a 16 month old with normal male external genitalia, developmental delay, and multiple minor anomalies including deformed ears. ${ }^{29}$ Like our patient, and that of Hagemeijer et $a^{26}$ described above, his weight, height, and head circumference were below the 3 rd centile, a consistent observation with these partial Xp duplications.

Other reports of $\mathrm{Xp}$ duplications are complicated by the patients being phenotypically female, despite carrying an intact $\mathrm{Y}$ chromosome. ${ }^{30-32}$ Scherer et $a l^{30}$ suggested that a duplication of the ZFX gene at Xp21.3 caused the sex inversion, with two active copies of ZFX overcoming the male determining action of ZFY. However, Sinclair et al ${ }^{17}$ have since shown that SRY is probably the testis determining gene, leaving the roles of $\mathrm{ZFX}$ and ZFY in sex determination uncertain. Furthermore, Schneider-Gadicke et $a l^{33}$ indicated that ZFX escapes $\mathrm{X}$ inactivation, in which case, if the model of Scherer et al ${ }^{30}$ were true, our patient and all cases of Klinefelter's syndrome, in spite of random $X$ inactivation, should be phenotypically female.

The concept of an X linked gene which, when duplicated to give two active copies, despite the presence of a $\mathrm{Y}$ chromosome, results in a female phenotype, is still valid.

Reviewing the published reports of genetic males with $\mathrm{Xp}$ duplications, our case with a duplication of $\mathrm{Xp} 22.1 \rightarrow \mathrm{p} 22.32$ and those of Narahara et $a l^{29}$ and Brondum-Nielson and Langkjaer ${ }^{34}$ with duplications of Xp22.1 $\rightarrow$ $\mathrm{p} 22.3$ and $\mathrm{Xp} 11.2 \rightarrow \mathrm{p} 21.2$, are phenotypically male, while those of Bernstein et al, ${ }^{31}$ Scherer et $a l,{ }^{30}$ and Stern et $a l^{32}$ with duplications of $\mathrm{Xp} 21 \rightarrow$ pter, Xp21.2 $\rightarrow$ p22.3, Xp21.2 $\rightarrow$ p22.2, and $\mathrm{Xp} 21 \rightarrow \mathrm{p} 22.3$ are phenotypically female.

This suggests that such a gene may be localised to Xp21.3, the only segment present in the phenotypic females but not the males. Unlike ZFX, it would be inactive on an inactivated $\mathrm{X}$ chromosome and only when present in two active copies would sex reversal result.

The patient described in this report is an XX male with the Wolf-Hirschhorn syndrome. His phenotype is the result of two separate exchange events involving both chromatids of $\mathrm{Xp}$ at paternal meiosis, an aberrant $\mathrm{X}-\mathrm{Y}$ interchange and an $\mathrm{X} ; 4$ translocation. The two rearrangements involve different $\mathrm{Xp}$ breakpoints and may be linked by a common clastogenic event or be coincidental. Whatever the cause, they have resulted in a complicated situation which was only resolved by the application of cytogenetic, in situ hybridisation, and molecular biological techniques.

We are very grateful to David Robinson and other staff of the Wessex Regional Genetics Laboratory for their help with this case.

1 Fuwimoto $A$, Wilson $M$. Growth retardation in WolfHirschhorn syndrome. Hum Genet 1990;84:296-7.

2 Lurie IW, Lazjuk GI, Ussora YI, et al. The WolfHirschhorn syndrome. Clin Genet 1980;17:375-84.

3 Quarrell OWJ, Snell RG, Curtis MA, et al. Paternal origin of the chromosomal deletion resulting in WolfHirschhorn syndrome. $f$ Med Genet 1991;28:256-9.

4 de la Chapelle A. The etiology of maleness in XX men. Hum Genet 1981;58:105-16.

5 Schempp W, Muller G, Scherer G, et al. Localization of Y chromosome sequences and $\mathrm{X}$ chromosomal replication studies in XX males. Hum Genet 1989;81:144-8.

6 Buckle VJ, Boyd Y, Fraser N, et al. Localisation of Y chromosome sequences in normal and XX males. $\mathcal{F}$ Med Genet 1987;24:197-203.

7 Muller U, Latt SA, Donlon T. Y-specific DNA sequences in male patients with 46,XX and 47, XXX karyotypes. $A m$

8 Mattei MG, Mattei JF, Ayme S, et al. X-autosome translocations: cytogenetic characteristics and their consequences. Hum Genet 1982; 61:295-309.

9 Seabright $M$. A rapid banding technique for human chromosomes. Lancet 1971;ii:971-2.

10 Buckle VJ, Craig IW. In situ hybridization. In: Davies KE, ed. Human genetic diseases. Oxford: IRL Press, 1986: 85-100. 
11 Page DC, Bieker K, Brown LG, et al. Linkage, physica mapping, and DNA sequence analysis of pseudoautosomal loci on the human $\mathrm{X}$ and $\mathrm{Y}$ chromosomes. Genomics 1987;1:243-56.

12 Miller SA, Dykes DD, Polesky HF. A simple salting ou procedure for extracting DNA from human nucleated cells. Nucleic Acids Res 1988;16:1215.

13 Feinberg AP, Vogelstein B. A technique for radiolabelling DNA restriction endonuclease fragments to high specific activity. Anal Biochem 1983;132:6-13.

14 Bernstein $\mathrm{R}$, Rosendorf J, Ramsay $\mathrm{M}$, et al. A unique dicentric $\mathrm{X} ; \mathrm{Y}$ translocation with $\mathrm{X} \mathrm{q}$ and $\mathrm{Yp}$ breakpoints: cytogenetic and molecular studies. Am $\mathcal{f}$ Hum Genet cytogenetic and

15 Affara NA, Ferguson-Smith MA, Magenis RE, et al. Mapping the testis determinants by an analysis of $\mathrm{Y}$-specific sequences in males with apparent $\mathrm{XX}$ and $\mathrm{XO}$ karyotype and females with XY karyotypes. Nucleic Acids Res 1987; 15:7325-42.

16 Palmer MS, Berta P, Sinclair AH, et al. Comparison of human ZFY and ZFX transcripts. Proc Natl Acad Sci USA 1990;87:1681-5.

17 Sinclair AH, Berta P, Palmer MS, et al. A gene from the human sex-determining region encodes a protein with homology to a conserved DNA-binding motif Nature 1990;346:240-4.

18 Knowlton RG, Nelson CA, Brown VA, et al. An extremely polymorphic locus on the short arm of the human $X$ chromosome with homology to the long arm of the $\mathrm{Y}$ chromosome. Nucleic Acids Res 1989;17:423-37.

19 Fraser NJ, Boyd Y, Brownlee GG, et al. Multi-allelic RFLP for M27-beta, an anonymous single copy genomic RFLP for M27-beta, an anonymous single copy genomic
clone at Xp11.3-Xcen. Nucleic Acids Res 1987;15:9616.

20 MacDonald ME, Haines JL, Zimmer M, et al. Recombination events suggest potential sites for the Huntington's disease gene. Neuron 1989;3:183-90.

21 Wilson MG, Towner JW, Coffin GS, et al. Genetic and clinical studies in 13 patients with the Wolf-Hirschhorn syndrome. Hum Genet 1981;59:297-307.

22 Anvret $M$, Nordenskjold $M$, Stolpe $L$. Molecular analysis of $4 p$ deletion associated with Wolf-Hirschhorn syndrome moving the 'critical segment' towards the telomere. Hum Genet 1991;86:481-3.
23 Buhler EM, Jurik LP, Voyame M, et al. Presumptive evidence of two active $\mathrm{X}$ chromosomes in somatic cells of a human female. Nature 1977;265:142-4.

24 Summitt RL, Martens PR, Wilroy RS. X-autosome translocation in normal mother and effectively 21 -monosomic daughter. $¥$ Pediatr 1974;84:539-46.

25 Brown C, Lafreniere RG, Powers VE, et al. Localization of the $\mathbf{X}$ inactivation centre on the human $\mathrm{X}$ chromosome in Xq13. Nature 1991;349:82-4

26 Hagemeijer A, Hoovers J, Smit EME, et al. Replication pattern of the $\mathrm{X}$ chromosomes in three $\mathrm{X}$ /autosoma translocations. Cytogenet Cell Genet 1977;18:333-48.

27 Schinzel A. Catalogue of unbalanced chromosome aberrations in man. Berlin: de Gruyter, 1983.

28 Stengel-Rutkowski S, Warkotsch A, Schimanek $P$, et al. Familial Wolf's syndrome with a hidden $4 p$ deletion by translocation of an $8 p$ segment. Unbalanced inheritance from a maternal translocation $(4 ; 8)(\mathrm{p} 15.3 ; \mathrm{p} 22)$. Case report, review and risk estimates. Clin Genet 1984; 25:500-21.

29 Narahara K, Kodama Y, Kimura S, et al. Probable inverted tandem duplication of Xp in a 46,Xp + Y boy. fpn f Hum Genet 1979;24:105-10.

30 Scherer G, Schempp W, Baccichetti C, et al. Duplication of an Xp segment that includes the ZFX locus causes sex inversion in man. Hum Genet 1989;81:291-4.

31 Bernstein R, Jenkins T, Dawson B, et al. Female phenotype and multiple abnormalities in sibs with a Y chromosome and partial $\mathrm{X}$ chromosome duplication: $\mathrm{H}-\mathrm{Y}$ antigen and $\mathrm{Xg}$ blood group findings. $\mathcal{f}$ Med Genet 1980;17:291-300.

32 Stern HJ, Garrity AM, Saal HM, et al. Duplication $\mathrm{Xp} 21$ and sex reversal: insight into the mechanism of sex determination. Am f Hum Genet 1990; 47(suppl):1.81(0153).

33 Schneider-Gadicke A, Beer-Romera P, Brown LG, et al. ZFX has a gene structure similar to ZFY, the putative human sex determinant, and escapes $\mathrm{X}$ inactivation. Cell 1989;57:1247-58.

34 Brondum-Nielson $\mathrm{K}$, Langkjaer $\mathrm{F}$. Inherited partial $\mathrm{X}$ chromosome duplication in a mentally retarded male. $\mathfrak{f}$ Med Genet 1982;19:222-36. 